\title{
Between text and stage: the theatrical adaptations of J.M. Coetzee's Foe
}

Kareesha Naidoo and Hermann Wittenberg

\begin{abstract}
Several of J.M. Coetzee's novels have been adapted successfully for the stage, both as theatrical and operatic versions, but these adaptations have not received much critical attention. This article examines the ways in which Peter Glazer and Mark Wheatley have adapted Coetzee's novel Foe (1986), resulting in two different and distinct stage productions, performed in the US and the UK respectively. In order to explore the complex relationship between the published text and the play versions, the article will ground itself in theories of adaptation, drawing extensively on work by Linda Hutcheon and Robert Stam and Alessandra Raengo. One of the key ideas in adaptation theory is that adaptive fidelity to the source text is neither possible nor desirable, but that adaptation is a more complex, multi-layered intertextual and intermedial interplay of fictional material. The article discusses the two play scripts and analyses the adaptive choices which underpin them and how these structure their meaning-making. Finally, the article also suggests that these scripts can be used to throw more light on Coetzee's enigmatic novel.
\end{abstract}

Foe is a story about telling stories. It is about whose story to tell and who has the power to tell it. It is about having a voice. (Mark Wheatley)

\section{Introduction}

J.M. Coetzee's Foe, published in 1986, is one of the author's most enigmatic and complex novels, attracting a large volume of critical scholarship, including a special issue of Journal of Literary Studies ${ }^{1}$ and numerous other articles, book chapters and theses. Foe is Coetzee's re-imagined version of Daniel Defoe classic novel Robinson Crusoe (1719), rewritten from a feminist and postcolonial point of view. Instead of privileging a male heroic figure, Coetzee's novel tells the story of a woman named Susan Barton, who is searching for her lost daughter. Robinson Cruso (Coetzee drops the 'e' of 'Crusoe') becomes a minor character in the story that is much more centred on the relationship between Susan and Friday. An adversarial relationship between Susan and Mr Foe, the author figure based on Daniel Defoe, foregrounds the intertextuality of Coetzee's text in which authorship and storytelling assume a central role. Coetzee's novel poses formidable challenges to a stage adaptation, and it is remarkable that not just one but 
two autonomous adaptations have been created, by Mark Wheatley in 1996 and by Peter Glazer in 2003.

Much critical response has focused on the novel's intertextual aspects, particularly by postcolonial and feminist scholars (Spivak 1990; Begam 1994; MacLeod 2006; Attwell 2015), but little attention has been given to either of these two theatrical ver- sions, apart from a brief mention in John Kannemeyer's recent biography, JM Coetzee: A Life in Writing(2012):

In March 1996 the Théâtre de Complicité performed an adaptation of Foe by Mark Wheatley in the West Yorkshire Playhouse in Leeds and afterwards toured the UK, but the actors found it difficult to bring to life in theatrical terms such a multi-levelled play. More successful was the adaptation that Peter Glazer produced in October 2003 at the University of California at Berkeley. (p. 411)

Given the wide critical interest in Coetzee's novels, and the potential insights that adaptations, as forms of interpretations, can provide, it is surprising that not much more attention has been given to the various adaptations in different media. Coetzee's work has in fact seen multiple adaptations, for example, the well-known film of Disgrace (2008), directed by Steve Jacobs and adapted for the screen by Anna Maria Monticelli. An earlier film version of In the Heart of the Country (1977), entitled Dust (1985), was directed by Marion Hänsel. Waiting for the Barbarians (1980) was adapted twice for the screen, though both film versions remained unrealized (Witten- berg 2014). Apart from film, there has been a growing volume of theatrical adaptations of his work, as seen most recently in Russian director Alexander Marine's stage adap- tation of Waiting for the Barbarians, performed in 2012 at the Baxter Theatre in Cape Town (Lindsay 2012), as well as an acclaimed operatic adaptation scored to music by Philip Glass (Wittenberg 2014). There were two stage adaptations of Disgrace per- formed in Europe in 2012, one by Hungarian director and producer Kornél Mun- druczó and another by Toneelgroep, a Dutch theatre company (Lindsay 2012). The novel Slow Man (2005) was also staged as an opera, with a libretto written by Coetzee himself (Kannemeyer 2012). Much earlier, there was also a stage version of In the Heart of the Country, entitled Hinterland, performed by Jeannette Ginslov at the 1998 Grahamstown Arts Festival, and another version, entitled Writing with Stones, was staged at the 2006 Arts Alive Festival in Johannesburg (Wittenberg 2014, p. 16). As one can see from this incomplete list of examples, there has been con- siderable interest shown in adapting Coetzee's works, including by the author himself, suggesting that adaption is an area that needs much more thorough critical engagement.

This article will read the play scripts of Foe and explore the adaptive processes of these stage versions as they rework the textual material of the novel. Although this study is primarily a textual, one since the performances themselves (or possible video recordings) were not available for study, the analysis is alert to the performativity of the works, and attention will be given to the non-dialogue elements as indicated by stage 
directions and other aspects of didascalia. Didascalia is a term which 'refers to everything in the play which is not dialogue, in other words the title, character list, foreword, prologue, epilogue, stage directions, and so on' (Keuris 1996, p. 64) and these are key aspects of the script that allow insight into the nature of the performance. Since both Wheatley and Glazer draw their dialogue directly from the novel, especially from passages of direct speech, it is therefore mostly in these non-dialogue elements of the plays that we can see the most significant adaptive departures from the novel. It is thus primarily in the didascalic elements of the scripts that the stage versions show their distinctive differences, both from each other and from the primary novelistic text.

Language, mostly conveyed through dialogue and speaking on the stage, is central to theatrical performance, especially when novels are adapted. But in the theatre language is also complemented by a range of other non-verbal ways of transmitting meaning. According to Mark Fleishman, '[t]he physical body forms part of the meaning-making process of almost all theatre where human performers appear live in front of an audience' (1997, p. 201). Any reading of a script needs to take into account the performative possibilities that arise when the 'written text is given life when it is raised from the page and set inside the body of the actor' (p. 201). We will therefore explore how the physical embodiment of the text, as well as other devices of theatre (for example, lighting, stage design, music) can allow a richer insight into a novel that may not be accessible in any other way.

\section{Background to the plays}

In 1996 Complicité, formally known as Theatre de Complicité, produced Mark Wheatley's stage version, co-directed by Annie Castledine and Marcello Magni. According to Wheatley, the novel as a whole is about storytelling and the proliferation of multiple stories: '[f]or me, the remarkable thing about Foe is its even-handedness. I found I had to go back time and time again to the novel to rediscover the weight of each of the main character's stories - Friday, Cruso and Foeand above all, Susan Barton' (n.d., p. 1). For Wheatley, Coetzee's novels told universal, human stories that did not limit themselves to 'the details of South African politics - a project necess- ary and difficult enough - but spoke about the wider concerns that they raised: race, language, culture, history' (n.d., p. 1). For Wheatley, adapting Foe was attractive pre- cisely because the novel raised larger questions about power, history and the role of stories to shape our sense of the past. In his adaptation, as we shall see, the primary historical trauma that we are confronted with is the submerged story of slavery, an issue which Coetzee's novel deals with, but perhaps in a less direct manner.

According to the co-director, Marcello Magni, the adaptation of the novel was a complex and challenging endeavour which stretched Complicitéin new directions:

Complicité often work by throwing up physical images. Moments and short scenes that capture themes and emotions close to the subject of the show. This work is sometimes tan- gential and indirect. The performers discover their own texts. Foe demands a completely different practical approach from us, we have another task: a text written by Mark Wheat- ley that presents a very specific journey that is remarkably intricate and profound. Through deep and rigorous work analysing the text we want 
to understand and respect the meaning and the implications presented in the world of FOE. When we have done this we will discover how to wed the text and the visual images and the words and move- ment vibrantly together. (n.d., p. 21)

It is evident that Magni, Castledine and Wheatley wanted to use the particular theatrical style and brand of a Complicité production by infusing their highly physical and visually dramatic style into the performance of a philosophically complex and tex- tually rich novel. Instead of simply using large sections of text from Coetzee's novel, and staging this as speech and dialogue, Complicité's main aim was rather the creation of vivid audio-visual effects, 'integrating text, music, image and action to create sur- prising, disruptive theatre' (Knapper 2010, p.166). Wheatley's version uses consider- ably less of the novel's text than Glazer's version and attempts to convey the book's meaning by seamlessly combining 'text, visual images and the words and movement' (Wheatley 1996, p. 244245).

The second adaptation was written by Peter Glazer, whotaught theatre at the Uni- versity of California, Berkley. Glazer subsequently also directed the play which was premiered at the university's Zellerbach Playhouse on 3 October 2003. Coincidently, Coetzee won his Nobel Prize one day before the opening of the play. Glazer worked on the play for nearly six years, explaining his attraction to the novel as follows:

[Foe] caught me right away. [Coetzee's] language is just so remarkable. He's a brilliant writer, but this is a very unique book.... That first paragraph was exciting to me as a writer, but even more, I could hear that language coming from the stage and I really loved that [Coetzee] was playing with such a huge icon of international culture, that being Robinson Crusoe. ... With Foe [I am] writing alongside the audience's expectations and using them to some extent, which is fascinating because Crusoe has such resonance. (Maclay 2003)

It is clear that Glazer immediately recognized Foe's stage potential, and his primary attraction is to the language of the novel that structures his play version. Glazer's play is much more verbal in orientation and thereby closely aligned with Coetzee's text. As we will see in the following analysis, Glazer is at pains to convey Coetzee's prose as faithfully and as comprehensively as possible. Much more of Coetzee's novel is brought to the stage in the form of extensive extracts from the dialogue.

\section{Theorizing adaptation}

In order to understand the different adaptive processes at work in Wheatley's and Glazer's versions more thoroughly, it is important to consider various theorizations of adaptation. Adaptation theory has focused mainly on processes of adapting novels to film, and while there is comparatively little scholarship on theatrical adap- tation, similar processes and issues are at stake that makefor considerable theoretical overlap. What does adaption entail? Linda Hutcheon describes adaptation generally as '[a]n acknowledged transposition of a recognizable other work or works' (2006, p. 8). Glazer and Wheatley openly acknowledge their work as adaptations of Coetzee's Foe, using the same title and following the plot closely. Both Glazer's and Wheatley's works are, in Hutcheon's terms, 'deliberate, announced, and extended revisitations of prior works' (2006, p. xiv). Given the substantive creative shifts which both Glazer and Wheatley introduce into their adaptations, 
these are not simply replications or repro- ductions, but rather "repetitions with variation" (Lieblein 2007, p. 2).

Commentaries on the relationship between the adapted and the original work have been beset with much prejudice. Hutcheon notes that Virginia Woolf, as early as 1926, called cinema a "parasite" and literature its "prey" and "victim"” (Hutcheon 2006, p. 3). Literature was generally considered a superior artform which film invariablytra- vestied. As McFarlane (1996, p. 4) put it, "literature will always have axiomatic superiority over any adaptation because of its seniority as an art form'. But at the same time, instead of just seeing adaptations as debasing and often vulgar corruptions of the more prestigious literary text, films can also paradoxically give novels cultural prestige and validity. Anthony Burgess (1975, cited in Elliott 2003, p. 15) satirized such popular validation, scornfully noting that '[e]very bestselling novel has to be turned into a film, the assumption being that the book itself whets an appetite for the true ful- filment - the verbal shadow turned into light, the word made flesh'. Indeed, successful film adaptations can become so culturally influential that the original novel lapses into obscurity. As Stam and Raengo (2005a, p. 4) put it, '[f]ilmic embodiment is seen as making literature obsolescent, retroactively revealing mere words as somehow weak and spectral and insubstantial'.

In this regard, one of the most problematic issues in adaptation is fidelity, or the question of an adaptation's faithfulness to the source text. McFarlane (1996, p. 8) suggests that '[d]iscussion on adaptation theory has been bedevilled by the fidelity issue, no doubt ascribable in part to the novel's coming first, in part to the ingrained sense of literature's greater responsibility in traditional critical circles'. But a focus on fidelity also suggests a limited and limiting approach to adaptation. Fidelity criticism assumes an unproblematic idea or ideal of originality and faithfulness, and furthermore disallows artistic licence and creative interpretation on the part of the adaptor. As we will see, both Wheatley's and Glazer's adaptations are versions that orient themselves towards the source text, but they also make several changes which alter the original: Glazer, for example, puts three distinct Susan characters on stage, thereby triplicating Coetzee's protagonist and foregrounding her centrality; similarly, Wheatley adds dialogue and scenes to his play that are not found in the novel.

A simplistic notion of fidelity, such as espoused by Thomas Leitch (2003), is there- fore not always the most effective way to judge an adaptation. For Leitch fidelity remains the central principle with which to judge or analyse adaptations: '[f]idelity is the most appropriate criterion to use in [analysing] adaptations' (p. 161). In recent scholarship, however, fidelity has increasingly been seen as controversial and discredited as simplistic. Julie Sanders (2006), for example, points out that the 'sheer impossibility of testing fidelity in any tangible way is surely also in question when we are dealing with labile texts [for example] a Shakespeare play' (p. 20). She proposes that '[a]daptation studies are, then, not about making polarized value judg- ments, but about analysing process, ideology and methodology' (p. 20). Stam and Raengo (2000) attempts to move beyond naïve conceptions of fidelity, but also recog- nizes its 
considerable purchase and influence in popular thinking: '[i]t is important to move beyond the moralistic and judgemental ideal of "fidelity". At the same time, we have to acknowledge at the outset that "fidelity", however discredited theoretically, does retain a grain of experiential truth' (p. 4).

In a subsequent study Stam and Raengo (2005a) propose another way of dealing with adaptation: instead of using an unproblematized idea of fidelity, it is preferable to see adaptation 'as a matter of the source novel's hypotext being transformed by a complex series of operations: selection, amplification, concretization, actualization, critique, extrapolation, analogization, popularization and reculturization' (p. 19). It is useful to look at each of these concepts more carefully, showing what these terms imply for the enterprise of adaptation. Understanding the process of selection is imperative for adaptation studies as it allows the adaptor to emphasize certain parts of the original work, but also to ignore other parts. Substantial parts of a novel necessarily need to be left out to produce a 90-minute film or stage production. Apart from time constraints, the limitations of the medium would also play a role in the selec- tion process. Amplification means that some parts are exaggerated or highlighted; con- versely this also implies that some parts are de-emphasized or disregarded. Again, this would largely depend on the medium the adaptor is working with. Concretization means that certain elements in the novel are made concrete and visible. This is especially true in theatrical terms, as intangible ideas can be made visible and actua- lized on the stage. In a novel, small details such as a character's emotions are described verbally; on stage this needs to be dramatized. These details can be given a concrete specificity on the stage.

As Stam also suggests, adaptation can serve as a critique of a novel, though neither Wheatley's nor Glazer's plays are critical or revisionist adaptations of Coetzee's novel. Foe is in itself already readable as a critique of an original text, namely Robinson Crusoe. As discussed above, Coetzee's novel is a critical re-interpretation of Robinson Crusoe, appropriating its characters and setting, and at the same time as creating a new story. Stam and Raengo's concept of extrapolation furthermore alerts us to the ways in which various elements within a novel might serve as a point of departure to move into new areas that are maybe only hinted at in the novel. This would again depend on the medium of adaptation. For theatre, this is important as the adaptor can choose which sections of the novel could be used as a spring-board for new ideas. Stam and Raengo also refer to a process in adaptation that they call analogization. This means that the adaptor chooses themes or elements in the novel and finds equivalents for the adap- tation. For example, a motif in a novel might not work as well on stage. Therefore, the adaptor finds an equivalent device that would work effectively for the medium. The last term that Stam and Raengo highlight is popularization, which means that through the adaptation a more complex and possibly inaccessible literary text is made more accessible to a general audience.

Margherita Laera (2014, p. 5) notes that some "theatre artists and scholars prefer the term "appropriation" to define their work because adaptation is perceived to be too linked to literary practices and text-based theatre, or because it suggests an idea of a derivative endeavour of lesser value than the "original" work'. This idea of appro- priation is also important to look in a study of the two theatrical adaptations. Foe is in this sense an appropriation of Robinson Crusoe as Coetzee has 
created a new work by re-envisioning Defoe's novels. Furthermore, appropriation is in itself a central matter in the novel, as we can see when Susan's story is used and re-told by the author, Mr Foe. Both the Wheatley and the Glazer plays themselves remain close to the source text and do not distort its meaning, but both also interrogate processes of appropria- tion critically.

\section{Dramatis personae}

It is important to consider the cast lists envisaged for the productions, and compare these with the characters that Coetzee employs in the novel. Keuris $(1996$, p. 65) states that 'the function of the list of characters is to give names to the various char- acters in the fictional dramatic world. The identification of the various characters though their names often goes hand in hand with bits of information about each of them'. In Coetzee's Foe there are comparatively few characters: Susan Barton, Friday, Cruso, the young girl who calls herself 'Susan Barton', the captain who rescues Susan, Friday; Jack (Mr Foe's servant boy), and finally Mr Foe. Friday and Susan are the main characters and the novel centres on their interactions. Cruso dies in the first section of the novel, reducing the principal character of Defoe's novel to a minor role. Though Mr Foe is only present in the third section, his presence is felt throughout the novel as Susan is speaking to him as she narrates the story of the island.

Wheatley's character list is simple and similar to the characters in Foe:

SUSAN: castaway

CRUSO: ruler of his island

FRIDAY: his manservant

FOE: a writer

JACK: Foe's servant

GIRL: Susan Barton, daughter of a brewer.

The list is directly adapted from Foe, providing little sense of any adaptive transpositions or changes. On the other hand, Glazer's character list is much more extensive and elaborate, showing his interpretive licence in adapting the novel, immediately revealing an approach that is not constrained by a simplistic notion of fidelity:

\section{Cast of Characters}

Three actresses share the role of Susan Barton, the central character and narrator of J. M. Coetzee's novel and this play. In each act, one of the three actresses takes the lead, living in the time and world of scenes more than the other two Susans, who act as narrators or a kind of Chorus. Each of the three Susans takes this lead role in successive acts - FIRST SUSAN is the castaway on Cruso's island in Act I, SECOND SUSAN pursues Mr. Foe in England with FRIDAY in Act II, and THIRD SUSAN confronts Foe in his lodgings in Act III.

Women

FIRST SUSAN - a British woman in her late 20 s or early 30s; incisive, educated, persistent, her ideals intact. 
SECOND SUSAN - the same; a bit more mature, cynical, on edge.

THIRD SUSAN - the same; more suspicious, stubborn; both more vulnerable and manipulative.

THE GIRL/SAILOR/NARRATOR - The Girl is a mysterious child of 12 to 15 who claims to be Susan's daughter; cheerful, unflappable, wilful.

Men

CRUSO - a British man in his 5os, decades away from civilization; resourceful, sullen, gaunt, stolid, private.

FRIDAY - an African man in his 20 s or early 30s; mute, serious, distant.

MR. FOE-Daniel (De)Foe, mid-5os; brilliant, worldly, elusive.

CAPTAIN SMITH/NARRATOR

DEAD CAPTAIN/SAILOR - also assists with costume changes, prop hand-offs, etc.

What is immediately striking is Glazer's triplication of the central Susan character. All three Susans are present simultaneously on stage, not only re-enforcing the importance and centrality of the character, but also clearly signalling Glazer's break with naturalistic stage realism. The device of the three Susans is also a significant departure from

Coetzee's novel, although each of the Susans represents one particular phase or iteration of the character, as she changes and matures through the development of the novel. Coetzee created Susan as a complex, multifaceted personality, and Glazer's adaptation amplifies this notion. Susan Barton is an important character in Foe as she acts as the narrator for the first three parts; she is also the driving force behind all the events that occur in the novel. Susan does not appear in Robinson Crusoe, which is one of the most significant changes Coetzee makes to his story, and the fact that Glazer stages three Susans in the play foregrounds Coetzee's own act of adap- tation. This choice of staging shows Glazer adopting a more complex approach to adaptation than merely reproductive fidelity.

In the following section, we will argue that although having three separate actresses portray one 'character' on stage may appear unconventional, it is an informed choice Glazer makes and it may alter the way we read the novel as a whole. The triplication of Susan leads to an even stronger, amplified female presence in the play, emphasizing Coetzee's gender-critical theme in his novel. The extract below is taken from Act Three, scene one, titled: $\quad$ s':

[In this next sequence, *THIRD SUSAN*'s speeches and argument are shared among the three SUSANS. FOE's [sic] is never aware of the trio as such. At first, his focus remains on *THIRD SUSAN*, even if one of the others is speaking. As the scene progresses and the argument builds, FIRST and SECOND SUSAN take *THIRD SUSAN*'s chair or place on the stage, and FOE focuses on them as though they were the same as *THIRD SUSAN* (which, in fact, they are!). Therefore the secondary SUSANS become, periodically, primary.] ...

*THIRD SUSAN* 
[more urgency]

'The story I desire to be known by is the story of the island. It commences with my being cast away there and concludes with the death of Cruso and the return of Friday and myself to England, full of new hope. Now you propose to reduce the island to an episode in the history of a woman in search of a lost daughter. This I reject!'

MR FOE

"Susan..."

SECOND SUSAN and *THIRD SUSAN*

"You err most tellingly in failing to distinguish

SECOND SUSAN

between my silences and the silences of a being such as Friday. Friday has no command of words and therefore no defense against being re-shaped day by day in conformity with the desires of others". (Glazer 2003, pp. 86-87)

In the above scene, the three Susans share the main role and Foe is not aware that Susan is in fact portrayed by three separate woman; his focus remains on the Third Susan. The dialogue is exactly the same as the novel, but Glazer's interpretation of the scene allows us to see shifts in verbalized speech and thought. The splitting of Susan needs to read as a device that distinguishes between the wordsthat are heard by Mr Foe (the words of Third Susan), and her inner thoughts or reflections which are not shared with Foe but allow us to get a sense of her true feelings. In the novel there is no such distinction: Susan's entire speech is directed at Foe. The play version thus intro- duces considerable dynamism and complexity into the dialogue, allowing us to see even more clearly how the power relations play out, and how Susan's voice is margin- alized and literally silenced on the stage. Coetzee's feminist stance, as articulated in the novel, becomes even more clearly articulated in Glazer's stage version. Through the Second and Third Susan alter egos on the stage, Glazer effectively dramatizes Susan's silencing.

Other changes in characters include the 'captain' and the 'dead captain', who also plays the narrator in certain sections, as well as assisting with on-stage costume changes and props. Despite the obvious changes in characters that Glazer brings to Coetzee's novel, it is evident that, overall, he attempts to be as faithful as he possibly can to the original text. This is evident when we consider the following remarks where he explains the use of quotations marks in the script:

Stage directions "in quotation marks" are taken directly from the novel. Indented lines indicate the beginning of paragraphs in Coetzee's book, when appropriate. "Double quo- tation marks" denote dialogue, as opposed to narration. 'Single quotation marks' are used to set off SUSAN's letters to MR FOE. The layout of the dialogue on the page is meant to support both the rhythm of Coetzee's language and sometimes the way the stories and ideas make meaning through the language. (unpaginated)

In the above comment, Glazer is highly conscious of and attentive to the question of fidelity, because he trying to remain as faithful as possible to Coetzee's text, and allow- ing readers of the play script a detailed insight into the extent of his use of original source material. Glazer respects Coetzee's writing and tries to incorporate it as Much as possible throughout the play. 
Intertextuality and appropriation in Wheatley's adaptation Wheatley's adaptation begins with complete darkness. The opening of the play's script reads as follows:

The sounds of the body, interior sounds: the beat of pulse, the run of blood, faint but rising. With these, underwater sounds, the muffled, heavy echoes heard under the sea. Light grows very slowly on the falling body of SUSAN. She is drowning. As she falls, the sounds of conversation rise - distant, indistinct. A figure appears, dimly discernable. Then another and another, until the space below SUSAN appears to hold a waiting crowd. Some are more substantial than others, some are mere shadows. They move little then very slowly. The conversing voices are theirs - disembodied. This is the space of death, the place before birth, the storing of memories. Among them is FOE but we are unable to distinguish him yet. (1996, p. 1)

In the above stage directionWheatley describes the space as the 'place of death' (p. 1), eliciting images associated with an 'underworld'. This opening scene is not taken directly from the novel, but could be understood as Wheatley attempting to stage the novel's unconscious, a composite dream-world in which elements of Coetzee's text resonate. Wheatley initially uses only voice and sounds to fill a darkened stage.

The imagery described is reminiscent of the final chapter of Foe, where the novel is most explicit about the trauma of slavery; here its presentation at the play's beginning is foreboding and uncanny, evoking similar imagery and tones: darkness, underwater sounds, shadowy figures, the rhythmic, muffled beat of a pulse, images of drowning and places of trauma and death.

Wheatley also used lighting as a key device to create an evocative and rich mise en scène, which sets the tone for the entire play. Similarly to Glazer, Wheatley has moved away from naturalistic depiction, and provides a suggestive and allusive first scene which, already at the start, reinforces the story's circular and retrospective structure.

The dialogue begins with three disembodied voices:

Voice 1: I was born in the year 1632, in the city of York. My father being a foreigner of Bremen. I was called Robinson Kreutznaer. But by the usual corruption of words in England, we are now called Crusoe...

Robinson Crusoe

Voice 2: Being shipwrecked, I came on shore -

Voice 3: From the ship I took two or three bags full of nails and spikes. (1996, p. 1)

The opening lines do not occur in Coetzee's novel, but are taken directly from Defoe's Robinson Crusoe. Wheatley therefore stages 'a going back to the origins' $(1996$, p. 11) where he not only reinterprets Foe but Robinson Crusoe. The play goes on with the voices uttering single sentences: 
Voice 2: Upon the sides of a square post I cut everyday a notch with my knife...

Voice 1: Robinson Crusoe, so my companions always call'd me -

[Another carries a journal and writes in it with a quill]

Voice2: ....and every seventh notch was as long again as the rest [...] $(1996, \mathrm{p} .1)$

The 'Crusoe' voiced here shows characteristics of Defoe's Crusoe and not Coetzee's, as Coetzee's Cruso did not keep a journal and was averse to recording his island experi- ences. It is evident from the very beginning of the play that Wheatley stages an inter- textual web of connections and meaning making which foregrounds the relationship between originals and their appropriations and adaptations. Wheatley is clearly not constrained by adaptive fidelity as he does not only use Foe as the primary text for this play, but he also looks back at Defoe's story.

In the first interaction between Susan and Foe, Wheatley also illustrates the tension between her story and the fictionalizing distortions that he, as the author, will make. The extract shows how Susan voices her story, but that Foe ignores her, preferring to listen to another voice and imagined sounds from an island. These voices, perhaps imaginable as Foe's inner thought processes, utter words which we can recognize as being part of Robinson Crusoe:

Susan: My name is Susan Barton. You have not heard a story like mine.

[FOE is revealed, listening to the voices]

Voice 2: And now it was when I began to keep a journal -

[hammering and sawing again]

Susan: [To FOE] I have just returned from a far-off place.... I have been castaway on a desert island....My name is Susan Barton....Mr Foe, I will say in plain terms what can be said and leave unsaid what cannot be said....I will not have lies told about me. I would rather be the author of my own story than have lies told about me. (p. 4)

In his staging Wheatley is drawing attention to the marginalization of Susan's story and the way an authorial imagination uses her story as a springboard for a form of fictionalization that ultimately writes her out of its central concerns. The 'voice' we hear is the voice of Robinson Crusoe, as yet a ghostly, disembodied figure on the stage, but as Wheatley's play suggests, becoming 'materialized' as a character in Defoe's novel. In presenting the following fragments, Wheatley allows us to see Defoe's imagination at work, creating the setting and character of his novel:

Voice 2: December fourteenth. I carried everything into the cave. ... December the seventeenth. From this day to the twentieth I placed shelves, and knocked up nails...

[Hammering]

Voice 4: I began to speak to Friday and teach him to speak to me. ... I let him into the mystery of gun powder and bullet and taught him how to shoot.

Voice 2: And now I began to be in some order within doors. Also I made me another table. Voice 3: From the ship I took two or three bags full of nails and spikes. (1996, pp. 2-3) 
'voices' can be seen to stage Defoe's creative process in crafting his famous novel: here he is seen to conceive of the figure of Crusoe and inventing an island within his own imagination but it is a story which is distinct from Susan's account. The voices seem to fade in and out amongst Susan's words, distracting Foe from listening to her. In Wheatley's play Defoe's authorial inventiveness is shown, showing how his novel emerged out of fantasy voices and his own creative imagination, rather than Susan's more matter-of-fact account. Wheatley's stage adaptation therefore concretizes the intertextuality of Foe much more clearly: in pre- senting multiple voices on the stage as heard by Defoe/Foe which drown out Susan's story, the play heightens our awareness of the intertextual relations which are foundational to Coetzee's novel.

\section{The island setting in Glazer's adaptation}

An examination of the didascalia related to set construction allows us insight into the way Glazer created the island setting, difficult to stage, of the story. Glazer and Wheat- ley chose very different paths when adapting the island location, with Wheatley, as we have seen, relying on sound and lighting effects. Glazer's approach is more strongly articulated through set design:

An open space, hopefully configured as a thrust or in the round. A stage of angled, raked surfaces might evoke the rocky, dry island of Act I which then haunts the successive acts. A ribbed structure upstage can serve as Cruso's hut ... evocative of the ribs of a sunken ship or the skeleton of a whale. (2003, p. 1)

Harry Schanker and Katherine Ommanney (1989, pp. 411-412) explain open-space techniques in the theatre: "the thrust stage [is a] a low platform stage that projects into the audience. Since the audience surrounds the thrust stage on three sides, conven- tional scenery should be placed deep on the stage to avoid blocking the audience's view'. On the other hand, '[a]rena stages (theat[re]-inthe-round) use a different approach. Since the audience completely surrounds the stage, scenery will undoubt- edly block the view of at least some of the spectators (pp. 411-412). Glazer has used a combination of these two staging techniques. Careful consideration was given to the symbolism of the stage design and props. As he explains: "[a] ribbed struc- ture upstage can serve as Cruso's hut ... evocative of the ribs of a sunken ship or the skeleton of a whale" (p. 1). The stage design elements have multiple uses in the play, and the 'ribbed structure', reminiscent of a sunken ship, can also be understood to pre- figure the ending with its imagery of a sunken slave ship. The stage (space) is open and consists of 'angled, raked surfaces' (p. 1), which evoke the novel's dry rocky island with its cliffs. It is evident that Glazer's set is capable of creating a flexible dramatic space that can be used for the entirety of the play with minimal scene changes. In Glazer's illustrative photograph of the set (designed by Kate Edmunds), we can clearly see the thrust. Reviewer Cindy Peng (2003, n.p.) notes, 'Edmunds' stage design, a flat, tilted spiral of wood planks with the skeleton of a ship's hull looming above is minim- alist without seeming bland, a harmonious, visually pleasing design with smooth curves and balanced lines'. From the image below, captured by Weiferd Watts, ${ }^{2}$ one can see that the entire stage suggests the appearance of the wooden deck of a ship. 
But the play is not just set on an island; it also needs to convey sea and aquatic imagery. The ocean is an integral element of the story and the final section of the novel partly takes place underwater. Like Wheatley, Glazer's play uses sound to bring the ocean to the stage. The opening of Glazer's play begins with the stage direction: 'Utter darkness and sounds of ocean' (p. 7). As the light slowly fades in, the audience is now focused on the action on stage. All three Susans are on stage and they take turns to speak; stage directions indicate that " $[t]$ hey now lie prone on three benches, face down, swimming, desperately" (p. 7). Not only does Glazer use sound to capture the island locale, the characters on stage make movements mimicking various activities associated with water such as paddling, swimming and rowing.

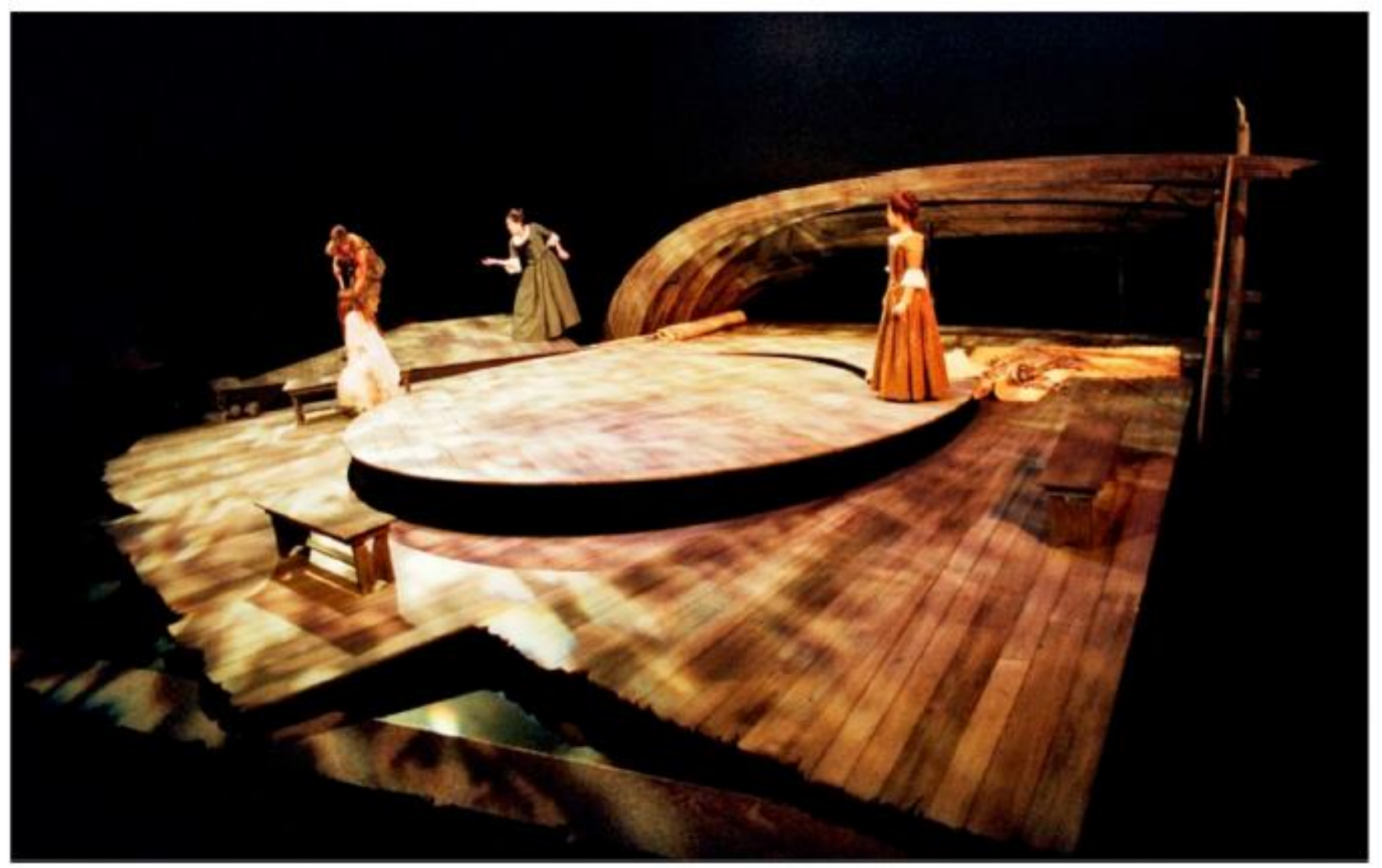

Figure 1. Act I Scene 9, 'The Terraces'.

Another way Glazer incorporates the ocean onto the stage is by having characters stare off into the vast distance from time to time. The stage is representative of the island and the ocean is where the audience sits. For example, in Act 1, scene 8, 'Cruso enters ... with one of his shoes in hand, sits to look at the ocean' (p. 36). Later in the same act First Susan asks where Cruso's ship had gone down and 'Cruso nods vaguely towards the water' (p. 36). The characters make subtle move- ments to indicate they are surrounded by water. These movements, coupled with the background sound of the sea, bring the ocean setting to the theatre. In the rescue scene (Act 1, scene 11) we read as follows: 'First Susan rushed out of the hut to the edge overlooking the water and falls to her knees' (p. 40). This is a movement made by 'Susan' to show she is overlooking the ocean as she sees a ship. Glazer then indicates a change on set, when '[sailors] lift the weak Cruso on [a 
stretcher] and carry him to the part of the stage which will now represent the ship' (41). Glazer makes it clear that they are no longer on the island and they have been rescued after being shipwrecked there for a year. When the action moves to the ship, "[s]ounds begin, or have already begun, of a ship at sea, creaking of timbers, water on the hull, wind.

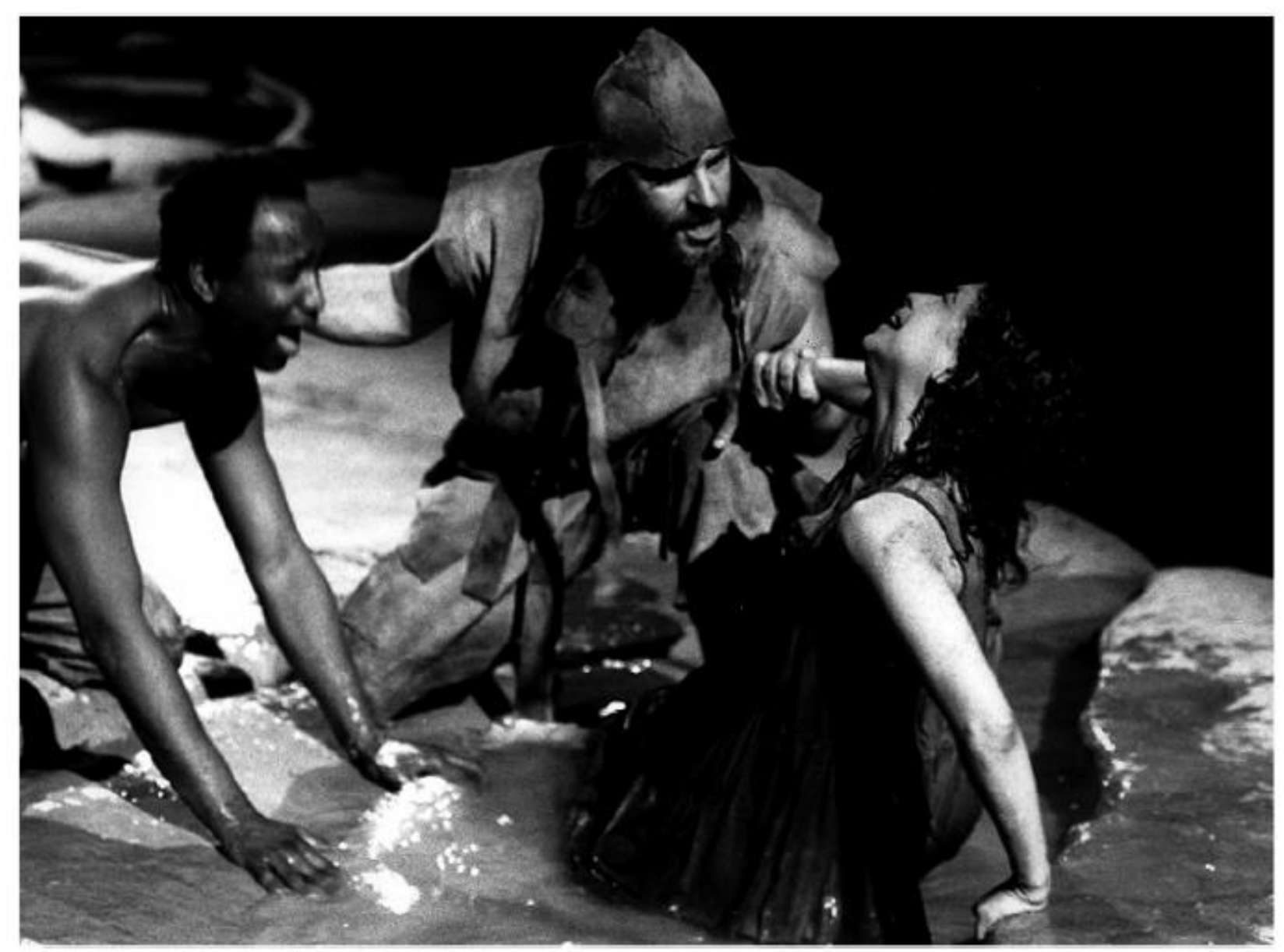

Figure 2. Friday (Patrice Naiambana), Cruso (Hannes Flaschberger) and Susan (Kathryn Hunter).

These sounds could gradually become more and more surreal as the scene progresses, or turn into music, creating more of an emotional than realist world' (p. 43). Overall Glazer's use of sound effects and body language appears to recreate the ocean locale effectively. On the other hand, Wheatley's adaptation addresses the challenge of the ocean and island very differently. As indicated above, Wheatley's theatrical style is considerably different from Glazer's. Wheatley's adaptation does make use of sound to provide ambiance and it is also used to indicate location changes. But in keeping with the phys- ical theatre style of Complicité, Wheatley uses large volumes of real water in his staging. The use of water on stage can be seen in a photograph taken by Simon Annand 3 at one of the play's performances: 
One can clearly see a pool of water on the stage and Susan's wet costume. It is unknown at what point in the play this photograph was taken; however, a reviewer, Paul Taylor (1996), recalls a scene from the play that illustrates the dramatic potential of water on the stage: 'Susan, demented by the noise of the wind, dips her head into a pool of water and all the sound suddenly switches off, creating, in a work preoccupied by silence, silence of dizzying intensity'. Although the approach of having an actual pool of water on stage might suggest that Wheatley's adaptation employs a realist representational mode, it evident that overall his is a minimalist staging, not interested in verisimilitude.

\section{Conclusion}

As we have seen, both of the adaptations of J.M Coetzee's Foe have approached the staging of the novel in different ways. Wheatley's and Glazer's versions address the challenges of staging a complex novel in different but ultimately persuasive ways. Both Wheatley and Glazer highlight the intertextuality of Coetzee's novel. Wheatley concretizes Foe's intertextual connection to Robinson Crusoe, as is particularly evident through the use of off- stage voices (representing Defoe's authorship) and Susan's onstage dialogue. The dramatic tension between Susan's story and the voices makes Coetzee's critical engagement with Defoe more concrete and visible. Similarly, Glazer's play also highlights the issue of intertextuality by literally bringing Defoe's and Coetzee's books on to the stage through repeated projections of pages from both Robinson Crusoe and Foe. Glazer incorporates Foe's dialogue to a much greater extent, making his adaptation appear closer to Coetzee's novel; however, the play is not constrained by a simplistic notion of fidelity as it makes use of non- realist elements such as the triplication of Susan Barton's character.

It is evident that the plays allow us to make sense of the novel in particular ways. Wheatley's staging refocuses our sense of the novel's engagement with questions of authorship, fiction and storytelling. As stated in the epigraph to this article, Wheatley is interested in telling a story: 'Foe is a story about telling stories. It is about whose story to tell and who has the power to tell it. It is about having a voice' (p. 11). He is interested in power and the voice, which not only reveals gendered asymmetries, but is also central to the question of slavery and the silencing of the black subject during the slave trade. Glazer's play, on the other hand, emphasizes Coetzee's postmo- dern sense of textuality more strongly, presenting a staging in which fictions, truth, dreaming and the endlessly open, intertextual worlds of fiction and the imagination are foregrounded. Both Glazer's and Wheatley's adaptations attempt to be faithful to Coetzee's text and not subject it to distorting interpretations. Nevertheless, neither play can be read in terms of simplistic notions of fidelity, and the various processes that Stam and Raengo outlined, namely 'selection, amplification, concretization, critique, extrapolation, analogization and popularization' (2005a, p. 19) give shape to the two respective versions and underpin various creative and inventive departures from the source text. Adaptation is a complex, multi-layered intertextual and intermedial inter- play of fictional materials. The plays both show how the complex process of adapting a novelistic text to the stage generates meanings that may exceed the information on the printed page. Overall then, it is clear 
that the respective play versions are not reduced, cut down and therefore inferior versions of the novel, but stage the source text in ways that allow viewers and readers a deeper sense of Coetzee's creative imagination.

\section{Acknowledgements}

Permission to cite was kindly granted by Professor Peter Glazer (University of California, Berkeley). We would also like to thank Simon Annand and Weiferd Watts for permission to use the photographs reproduced in this article. Lastly, I would like to thank Claire Gilbert from Com- plicité for sending me research material. The support of the National Research Foundation of South Africa (NRF) and the research fund of the University of the Western Cape are gratefully acknowledged.

\section{Notes}

1. Issue 5 Volume 2, June 1989.

2.Glazer, Foe. Unpublished stage adaptation of J.M. Coetzee's novel Foe. (2003). Photogra- pher: Weiford Watts.

3.Complicité. Notes. Unpublished, Undated. Source: Complicité achieve. Photographer: Simon Annand. 


\section{References}

Attwell, D., 2015. J.M Coetzee and the life of writing. Auckland Park: Jacana.

Begam, R., 1994. Silence and mut(e)ilation: white writing in J.M Coetzee's Foe. The South Atlantic Quarterly, 93 (1), 112-129.

Coetzee, J.M., 1986. Foe. London: Penguin Books. Complicité., n.d. Notes. Unpublished. Complicité archive.

Elliott, K., 2003. Rethinking the novel/film debate. Cambridge: Cambridge University Press. Fleishman, M., 1997. Physical images in the South African theatre. South African Theatre Journal, 11, 199-214.

Glazer, P., 2003. Foe. Unpublished stage adaptation of J.M. Coetzee's novel Foe. Hutcheon, L. 2006. A theory of adaptation. New York: Routledge.

Kannemeyer, J.C., 2012. J.M Coetzee: a life in writing. Cape Town: Jonathan Ball Publishers. Keuris, M. 1996. The play: a manual. Pretoria: J.L van Schaik Publishers.

Knapper, S., 2010. Shifting under/soaring over the boundaries of Europe. In: M. Delgado and D. Revellato, eds. Contemporary European theatre directors. New York: Routledge. Laera, M., 2014. Theatre and adaptation. London: Bloomsbury.

Leitch, T., 2003. Twelve fallacies in contemporary adaptation. Special film issue part two: new and/or neglected approaches to understanding moving images. Criticism, 45 (2), 167-171. Lieblein, L., 2007. Review of Linda Hutcheon: a theory of adaptation. Borrowers and Lenders: The Journal of Shakespeare and Appropriation. Available from: http://www.borrowers.uga.edu/781621/show [Accessed November 2015].

Lindsay., 2012. Books live. New European Theatre Adaptations of JM Coetzee's Disgrace. 31

May 2012. Available from: http://bookslive.co.za/blog/2012/05/31/new-europeantheatre- adaptations-of-jm-coetzees-disgrace-plus-new-book-on-the-way/ [Accessed November 2015]. Maclay, K., 2003. Theater professor stages adaptation of J.M. Coetzee's Foe. Rev. of Foe by Peter Glazer. UC Berkeley Drama Department, California. UC Berkley News. Available from: http://www.berkeley.edu/news/media/releases/2003/o9/19_glazer.shtml [Accessed 10 July 2015].

MacLeod, L., 2006. Do we of necessity become puppets in a story: or narrating the world: on speech. Silence and discourse in J.M Coetzee's Foe. Modern Fiction Studies, 52 (1), 1-13. McFarlane, B., 1996. Novel to film: an introduction to adaptation theory. Oxford: Clarendon Press.

Sanders, J., 2006. Adaptation and appropriation. London: Routledge.

Schanker, H.H. and Ommanney, K.A., 1989. The stage and the school. New York: McGraw Hill Companies.

Spivak Chakravorty Gayatri. 1990. Theory in the margin: Coetzee's Foe reading Defoe's 'Crusoe/Roxana.' English in Africa, 17 (2), 1-23.

Stam, R. and Raengo, A., 2000. Film theory: an introduction. New York: Blackwell Publishing.

Stam, R. and Raengo, A., 2005a. Literature and film: a guide to the theory and practice of film adaptation. Malden, MA: Blackwell Publishing. 
Taylor, P., 1996. Theatre: Foe; West Yorkshire Playhouse, Leeds. Rev. of Foe by Mark Wheatley. Theatre de Complicité, London. Available from: http://www.independent.co.uk/arts- entertainment/theatre-foe-west-yorkshireplayhouse-leeds-1341028.html [Accessed 16 May 2015].

Wheatley, M. 1996. Foe: second draft. TS National English Literary Museum, Grahamstown.

Wheatley, M. n.d. Putting the story on stage. Complicité notes. Unpublished. Complicité archives.

Wittenberg, H. 2014. Two Screenplays. ed. Cape Town: UCT Press. 